\title{
Antimicrobial peptides in lung transplant recipients with bronchiolitis obliterans syndrome
}

\author{
R.L. Anderson*,\#, P.S. Hiemstra\#, C. Ward*, I.A. Forrest*, D. Murphy*, D. Proud", \\ J. Lordan*, P.A. Corris* and A.J. Fisher*
}

ABSTRACT: Mechanisms other than classical alloimmunity are implicated in the pathogenesis of bronchiolitis obliterans syndrome (BOS). It was hypothesised that antimicrobial peptides (AMPs), elements of the innate immune response, have a role in BOS pathogenesis.

Pulmonary expression of the neutrophil-derived AMPs human cathelicidin (hCAP)-18/LL-37 and $\alpha$-defensins (human neutrophil peptides (HNP) 1-3), and the epithelial cell-derived AMPs human $\beta$-defensin (hBD)-2, elafin and secretory leukoprotease inhibitor (SLPI) were measured in stable lung transplant recipients and those with BOS. The relationship between airway pathogens and AMP levels was examined.

Bronchoalveolar lavage (BAL) was performed on 44 lung transplant recipients (30 stable, 14 with BOS). BAL was cultured for pathogens and ELISA for AMPs was performed. The presence of airway pathogens was associated with significantly increased levels of neutrophil-derived and epithelial-derived AMPs. When patients without pathogens in BAL fluid were analysed, eight recipients with BOS had elevated hCAP-18/LL-37 and HNP 1-3 compared with 25 stable recipients. hBD-2 and elafin levels were comparable in BOS and stable recipients, but SLPI levels were reduced in BOS.

Bronchiolitis obliterans syndrome is associated with elevated airway human cathelicidin 18/ LL-37 and human neutrophil peptides 1-3 from activated neutrophils, even in the absence of pathogens. Together with reduced airway secretory leukoprotease inhibitor this may favour nonalloimmune airway injury with reduced antiprotease defence and increased neutrophil degranulation.

KEYWORDS: Antimicrobial peptides, bronchiolitis obliterans syndrome, lung transplantation, secretory leukoprotease inhibitor

ung transplantation provides a realistic therapy for selected patients with endstage lung disease; however, long-term survival is limited to only $49 \%$ at 5 yrs. The main cause of death in lung transplant recipients surviving $>1 \mathrm{yr}$ is obliterative bronchiolitis [1, 2]. This manifests histologically by chronic inflammation and fibroproliferative repair in the small- and medium-sized airways, eventually leading to luminal obliteration. The clinical correlate, bronchiolitis obliterans syndrome (BOS) presents with progressive, irreversible, airflow obstruction and is diagnosed by a fall in forced expiratory volume in one second (FEV1) to $<80 \%$ of the best result achieved post-transplant in the absence of other causes of graft dysfunction. Frequent acute rejection episodes are a risk factor for BOS [3-5] and, to date, it has been attributed to a manifestation of chronic rejection occurring via alloimmune mechanisms. However, BOS is associated with neutrophilia in both bronchoalveolar lavage (BAL) fluid and on endobronchial biopsy [6-9] rather than a pure lymphocytic infiltrate. Despite the advent of more effective immunosuppression, reductions in the frequency of acute rejection have not been mirrored by reductions in the prevalence of BOS [10]. This raises doubts as to whether alloimmunity represents the only, or even the predominant mechanism in BOS pathogenesis.

The transplanted lung is exposed to the environment and has a highly developed innate immune system to protect against microorganisms. An innate immune response may induce injury directly by attracting inflammatory cells or by

\section{AFFILIATIONS}

*Cardiopulmonary Transplant Unit, Freeman Hospital, Institute of Cellular Medicine Newcastle University, Newcastle upon Tyne, UK. \#Dept of Pulmonology, Leiden University Medical Centre, Leiden, The Netherlands.

"Respiratory Research Group, University of Calgary, Calgary, $A B$, Canada.

\section{CORRESPONDENCE}

R.L. Anderson, Dept of Pulmonology, Leiden University Medical Centre, Leiden, The Netherlands. Fax: 31715154691

E-mail: R.Anderson@lumc.nl

Received:

August 232007

Accepted after revision:

April 272008

SUPPORT STATEMENT

R.L. Anderson, D. Murphy and

P.A. Corris were supported by Longterm Research Fellowships from the European Respiratory Society.

R.L. Anderson is also the recipient of an International Society for Heart and Lung Transplant fellowship.

I.A. Forrest was supported by a Medical Research Council fellowship and C. Ward was supported by a Medical Research Council project grant. J. Lordan was supported by the McPhail Trust. D. Proud holds a Canadian Research Chair in Inflammatory Airway Diseases.

STATEMENT OF INTEREST

A statement of interest for A.J. Fisher is available at www.erj.ersjournals. com/misc/statements.shtml

European Respiratory Journal Print ISSN 0903-1936 Online ISSN 1399-3003 
orchestrating subsequent adaptive immune responses acting as "danger signals", which could induce alloimmunity [11].

Antimicrobial peptides (AMPs) are cationic peptides that form essential elements of the innate immune system. The AMPs found in human airways include a human cathelicidin (hCAP)18/LL-37, $\alpha$ - and $\beta$-defensins, and the proteinase inhibitors secretory leukoprotease inhibitor (SLPI) and elafin [12, 13]. Their release is stimulated by inflammatory cytokines and microbial products and they act directly as endogenous antibiotics against a range of microorganisms [14-16]. The AMPs also modulate inflammation and immunity and influence repair processes. They have chemotactic activity for neutrophils, eosinophils, monocytes, dendritic cells and T-cells. Additionally, they affect maturation and upregulate the endocytic capacity and co-stimulatory molecule expression of dendritic cells, and promote the repair of epithelial surfaces by cell proliferation and inhibition of apoptosis [17-21]. AMPs play a key role in orchestration of the subsequent adaptive cellular or humoral response to injury favouring a repair response.

The present authors hypothesised that expression of the AMPs in the airway of lung transplant recipients would be increased in the presence of airway pathogens and in the presence of BOS. This would contribute to immune cell recruitment, proinflammatory chemokine release and creation of an environment favouring airway damage and subsequent epithelial injury or repair. The authors aimed to investigate levels of AMPs derived from both neutrophils and epithelial cells, in the airways of stable lung transplant recipients and those with BOS and to determine the relationship between airway pathogens and AMP levels.

\section{MATERIALS AND METHODS Study population}

Lung transplant recipients undergoing follow-up at the Cardiopulmonary Transplant Unit (Freeman Hospital, Newcastle Upon Tyne, UK) were recruited. BOS was diagnosed according to standard International Society for Heart and Lung Transplantation (ISHLT) criteria [22]. Patients undergoing either surveillance or investigative bronchoscopies were eligible for inclusion in the study. Recipients with biopsy-proven acute rejection, representing a predominantly lymphocytic process, were excluded.

The routine patient immunosuppressive regime comprised of prednisolone, cyclosporine and azathioprine. Tacrolimus and/ or mycophenolate mofetil were substituted for cyclosporine and azathioprine, respectively, as clinically indicated. Some recipients with $\mathrm{BOS}$ received total lymphoid irradiation and/ or long-term azithromycin therapy according to local protocols. Microbiological prophylaxis against bacterial infection was prescribed in accordance with local protocols: flucloxacillin/metronidazole/nebulised colomycin $\leqslant 1$ week posttransplant based on pre-transplant and donor microbiology; nebulised colomycin for patients with Pseudomonas aeruginosa pre-transplant and/or BAL positivity for P. aeruginosa; cotrimoxazole for Pneumocystis carinii prophylaxis after 1 week.

Ethical approval for the present study was granted by the Local Research Ethics Committee (Newcastle and North Tyneside Ethics Committee, Newcastle upon Tyne) and informed consent was received from all study patients.

\section{Sampling}

Bronchoscopy (Olympus FB 45.5; Olympus, Tokyo, Japan) was performed in patients pre-medicated with i.v. midazolam. BAL was performed using $180 \mathrm{~mL}$ normal saline instilled into the right middle lobe or lingula of the transplanted lung. Fluid was recovered by gentle suction and then pooled. A portion was evaluated for the presence of bacteria, viruses and fungi by standardised microbiological culture methods using selective agars and extended culture times. Any bacterial growth was considered positive. In total, 6-8 transbronchial biopsies were taken to exclude acute rejection based on ISHLT criteria.

BAL fluid was gauze-filtered and centrifuged. The acellular portion was then stored at $-80^{\circ} \mathrm{C}$ until analysis by ELISA and Western blot. A total and differential cell count was performed using a Nebhauer haemocytometer and Giemsa-stained cytospin preparations. There is currently no consensus on methodology to accurately determine the dilution factor when measuring components in BAL. The European Respiratory Society Task Force recommendations were followed and a standardised approach with no correction for protein levels was used [23].

\section{ELISA}

Established sandwich ELISAs were used to determine AMP levels in the cell-free BAL supernatant. Commercially available kits were used for human neutrophil $\alpha$-defensins (human neutrophil peptides (HNP) 1-3) and elafin from Hycult Biotechnology (Uden, the Netherlands), and for interleukin (IL)-8 from Biosource International (Nivelle, Belgium). ELISAs were performed according to manufacturer's instructions.

Human $\beta$-defensin (hBD-2) ELISA was performed using welldefined methodology [24]. SLPI, hCAP18/LL-37 and human neutrophil elastase ELISAs were measured on ELISA systems developed at Leiden University Medical Centre (Leiden, The Netherlands) [25, 26].

\section{Gel electrophoresis and Western blotting for hCAP-18/ LL-37 and SLPI}

Electrophoresis and Western blotting were performed on selected representative samples, (eight stable and eight BOS). This was to determine the presence of intact hCAP-18 and its cleavage to LL37 , and the presence of SLPI and its degradation products. Samples were subjected to SDS-PAGE on a $16.5 \%$ Tris/Tricine gel. Separated proteins were transferred to a polyvinylidenedifluoride membrane (Bio-Rad, Hercules, CA, USA). Nonspecific binding sites were blocked overnight. The membrane was then incubated for $1 \mathrm{~h}$ with mouse monoclonal anti-LL-37 antibody-1.1C12 for LL-37 [27] and with polyclonal rabbit antiSLPI immunoglobulin G for SLPI [26]. Secondary antibodies were horseradish peroxidase-conjugated goat anti-mouse for LL-37 and swine anti-rabbit for SLPI (DAKO, Glostrup, Denmark). The enhanced chemoluminescent Western blotting detection system was used to reveal immunoreactivity.

\section{Statistical analysis}

Data were initially assessed for normality. None of the data on AMP levels was normally distributed so nonparametric tests were used for analysis. Nonparametric data are presented as median (range); while normally distributed data are expressed as mean $\pm \mathrm{SD}$. Differences between groups were assessed using unpaired t-tests and the Kruskal-Wallis test. Where there were 
significant differences between groups on the Kruskal-Wallis test, further comparisons were tested with the Mann-Whitney U-test. A Bonferroni-Holm correction was used to correct for multiple comparisons between groups thus the threshold for significant $p$-values is sometimes $<0.05$. Correlations were assessed using Spearman rank correlation.

\section{RESULTS}

In total, 62 lung transplant recipients (34 female and 28 male) were evaluated for the present study. Of the 62 patients, 14 had BOS according to ISHLT criteria: BOS $0-\mathrm{p}, \mathrm{n}=2$; BOS $1, \mathrm{n}=2$; BOS 2, n=6; and BOS $3, n=4$. Of the remaining 48 patients, 18 had acute rejection ISHLT grade two or higher on transbronchial biopsy and 30 had stable lung function without evidence of acute rejection or BOS. The 18 patients with acute rejection were excluded according to the pre-defined exclusion criteria. Patient demographics and pre-transplant diagnoses are shown in table 1. There were no sex or age differences between the two groups. Treatment at the time of BAL sample is shown in table 2. The BOS group were significantly longer from time of transplant than the stable group.

\section{Neutrophils, IL-8 and neutrophil elastase}

The degree of airway neutrophilia, BAL, IL-8 and human neutrophil elastase (HNE) concentrations together with AMP levels in BAL fluid were compared between stable recipients

\section{TABLE 1 Patient demographics}

\begin{tabular}{|c|c|c|c|}
\hline & Stable & BOS & p-value ${ }^{\#}$ \\
\hline Subjects & 30 & 14 & \\
\hline Sex $M / F$ & $13 / 17$ & $8 / 6$ & \\
\hline Age yrs & $43 \pm 11$ & $33 \pm 18$ & 0.190 \\
\hline Days after transplant & $270 \pm 272$ & $744 \pm 579$ & 0.004 \\
\hline \multicolumn{4}{|l|}{ Diagnosis prior to transplant } \\
\hline CF & 11 & 8 & \\
\hline Emphysema & 10 & 3 & \\
\hline Fibrosis & 4 & 2 & \\
\hline $\mathrm{PPH}$ & 1 & 1 & \\
\hline Non-CF cystic disease & 4 & & \\
\hline \multicolumn{4}{|l|}{ BOS stage } \\
\hline Stage 0-p & & 2 & \\
\hline Stage 1 & & 2 & \\
\hline Stage 2 & & 6 & \\
\hline Stage 3 & & 4 & \\
\hline \multicolumn{4}{|l|}{ Transplant operation } \\
\hline Single & 6 & 3 & \\
\hline Bilateral & 21 & 10 & \\
\hline Heart-lung & 3 & 1 & \\
\hline Microbiology results & & & 0.191 \\
\hline Culture positive & $7(23)$ & $7(50)$ & \\
\hline Pseudomonas aeruginosa & 5 & 6 & \\
\hline Aspergillus fumigatus & 1 & 1 & \\
\hline Stenotrophomonas maltophilia & 1 & & \\
\hline
\end{tabular}

Data are presented as $n$, mean \pm SD or $n(\%)$, unless otherwise stated. BOS: bronchiolitis obliterans syndrome; M: male; F: female; CF; cystic fibrosis; $\mathrm{PPH}$ : primary pulmonary hypertension. ${ }^{*}$ : between groups.

\begin{tabular}{|c|c|c|c|}
\hline \multirow[t]{2}{*}{ TABLE 2} & \multicolumn{3}{|c|}{$\begin{array}{l}\text { Treatment regime at the time of bronchoalveolar } \\
\text { lavage sample }\end{array}$} \\
\hline & & BOS & Stable \\
\hline \multicolumn{2}{|c|}{ Cyclosporine, azathioprine, prednisolone } & $3(21)$ & $5(17)$ \\
\hline \multicolumn{2}{|c|}{ Tacrolimus, azathioprine, prednisolone } & $1(7)$ & $10(33)$ \\
\hline \multicolumn{2}{|c|}{ Tacrolimus, MMF, prednisolone } & & $1(3)$ \\
\hline \multicolumn{2}{|c|}{ Cyclosporine, prednisolone } & $1(7)$ & $1(3)$ \\
\hline \multicolumn{2}{|c|}{ Tacrolimus, prednisolone } & $6(43)$ & $3(10)$ \\
\hline \multicolumn{2}{|c|}{ Azathioprine, prednisolone } & & $2(7)$ \\
\hline \multicolumn{2}{|c|}{ Tacrolimus, azathioprine } & $2(14)$ & $3(10)$ \\
\hline \multicolumn{2}{|c|}{ Cyclosporine, azathioprine } & & $5(17)$ \\
\hline \multicolumn{2}{|l|}{ Tacrolimus } & $1(7)$ & \\
\hline \multicolumn{2}{|l|}{ Azithromycin } & $6(43)$ & \\
\hline \multicolumn{2}{|c|}{ Total Iymphoid irradiation } & $6(43)$ & \\
\hline
\end{tabular}

Data are presented as $\mathrm{n}(\%)$. BOS: bronchiolitis obliterans syndrome; MMF: mycophenolate mofetil.

and those with BOS (table 3). Recipients with BOS had a significantly higher percentage of neutrophils present and increased levels of HNE. IL-8 levels were not significantly different between BOS and stable recipients. Levels of the neutrophil-derived AMPs hCAP-18/LL-37 and HNP 1-3 were significantly increased in BOS even in the absence of a significantly higher total neutrophil count. There was no significant difference in levels of the epithelial-derived AMPs elafin and hBD-2 between BOS and stable recipients. SLPI, an epithelial-derived AMP with potent proteinase inhibitory activity, was present in significantly lower levels in the BAL fluid of recipients with BOS compared with stable recipients.

As the presence of pathogens could have a major confounding effect on neutrophil influx and AMP expression in the airway, the data were re-examined in both stable and BOS recipients

\begin{tabular}{|c|c|c|c|}
\hline $\begin{array}{l}\text { Compar } \\
\text { fluid in s } \\
\text { with bro }\end{array}$ & $\begin{array}{l}\text { etween bron } \\
\text { ransplant rec } \\
\text { tis obliterans }\end{array}$ & $\begin{array}{l}\text { choalveolar lav } \\
\text { ipients and rec } \\
\text { syndrome }(B C\end{array}$ & $\begin{array}{l}\text { lage } \\
\text { ipients } \\
\text { DS) }\end{array}$ \\
\hline & Stable & Bos & p-value ${ }^{\#}$ \\
\hline Subjects & 30 & 14 & \\
\hline Total neutrophils $\times 10^{4}$ & $0.3(0-63)$ & $3.7(0-205)$ & 0.088 \\
\hline Neutrophils \% & $2.1(0-72.4)$ & $19.7(0-100)$ & 0.008 \\
\hline $\mathrm{IL}-8 \mathrm{pg} \cdot \mathrm{mL}^{-1}$ & $42(0-8759)$ & $590(16.5-15008)$ & 0.044 \\
\hline $\begin{array}{l}\text { Human neutrophil } \\
\text { elastase } \mathrm{ng} \cdot \mathrm{mL}^{-1}\end{array}$ & $7(1-2886)$ & $75(2-454)$ & 0.063 \\
\hline hCAP-18/LL-37 $\mathrm{ng} \cdot \mathrm{mL}^{-1}$ & $0.4(0-21)$ & $10(1-38)$ & 0.001 \\
\hline HNP $1-3 \mathrm{ng} \cdot \mathrm{mL}^{-1}$ & $4(0-3212)$ & $510(0-9512)$ & 0.008 \\
\hline $\mathrm{hBD}-2 \mathrm{pg} \cdot \mathrm{mL}^{-1}$ & $137.5(0-2450)$ & $73(0-3490)$ & 0.959 \\
\hline SLPI $\mathbf{n g} \cdot \mathrm{mL}^{-1}$ & $156(56-1926)$ & $44(0-525)$ & $<0.001$ \\
\hline Elafin $\mathrm{pg} \cdot \mathrm{mL}^{-1}$ & $607(0-15541)$ & $0(0-4827)$ & 0.749 \\
\hline
\end{tabular}

Data are presented as $\mathrm{n}$ or median (range), unless otherwise stated IL: interleukin; hCAP; human cathelicidin: HNP: human neutrophil peptides; hBD: human $\beta$-defensin; SLPI: secretory leukoprotease inhibitor.

\#: Kruskal-Wallis 
TABLE 4 Patient characteristics and bronchoalveolar lavage parameters in stable recipients and recipients with bronchiolitis obliterans syndrome (BOS) grouped according to the presence of cultured pathogens

\begin{tabular}{|c|c|c|c|c|c|c|}
\hline & \multicolumn{3}{|c|}{ Stable patients } & \multicolumn{3}{|c|}{ Bos } \\
\hline Sex M/F & $10 / 13$ & $3 / 4$ & & $4 / 4$ & $4 / 2$ & \\
\hline Age yrs & $42(22-62)$ & $38(22-55)$ & NS & $30(18-59)$ & $29(21-58)$ & NS \\
\hline Neutrophils \% & $1.4(0-26.6)$ & $46.6(1.6-72.4)$ & 0.003 & $18(0-91.4)$ & $22(2.2-99.6)$ & 0.699 \\
\hline IL-8 pg $\cdot \mathrm{mL}^{-1}$ & $25(0-2320)$ & $1664(45-8759)$ & 0.001 & 369 (17-3730) & $962(105-15008)$ & 0.302 \\
\hline $\mathrm{HNE} \mathbf{n g} \cdot \mathrm{mL}^{-1}$ & $6(1-733)$ & 1374 (13-2886) & $<0.001$ & 95 (2-454) & $51(13-174)$ & 0.561 \\
\hline
\end{tabular}

Data are presented as $n$ or median (range), unless otherwise stated. M: male; F: female; IL: interleukin; HNE: human neutrophil elastase; NS: nonsignificant. ${ }^{\#}$ : MannWhitney.

with and without positive cultures of BAL fluid (table 4). In stable recipients the presence of pathogens was associated with a significant increase in BAL neutrophilia and elevation of both IL-8 and HNE. However, in recipients with BOS, the presence of pathogens was not associated with a higher total neutrophil count or neutrophil percentage or with any difference in levels of IL-8 or HNE.

\section{Neutrophil-derived AMPs and epithelial cell-derived AMP hBD-2}

The AMPs derived predominantly from neutrophils, LL-37 and HNP 1-3, were significantly higher in stable transplant recipients who had had pathogens cultured from BAL compared with stable recipients who were culture negative. Interestingly, however, in recipients with BOS there was no additional AMP response to the presence of pathogens. The data showed that even in the absence of pathogens there was a significantly higher level of both LL-37 and HNP 1-3 in recipients with BOS compared with stable recipients (fig. 1).

Neutrophils store the precursor cathelicidin hCAP-18 in their specific granules. Proteolytic processing to the active peptide LL-37 occurs after neutrophil stimulation [28]. The hCAP-18/ LL-37 ELISA used was based on antibodies raised against LL37 and, therefore, detected both the precursor hCAP-18 and processed forms of hCAP-18 containing the LL-37 sequence. Western blot analysis was utilised to differentiate intact hCAP18 from processed hCAP-18 containing LL-37 in the BAL samples. The results showed that the ratio between hCAP-18 and LL-37 differs among transplant recipients. Some recipients have a much higher ratio of active peptide to hCAP-18 than others (fig. 2).

hBD-2 is derived mainly from epithelial cells and is not produced by neutrophils. There was no significant difference in levels of hBD-2 between groups (fig. 3).

\section{Proteinase inhibitors}

The two AMPs with antiproteinase activity, elafin and SLPI, are produced predominantly by epithelial cells. There were no significant differences in the levels of elafin found between any
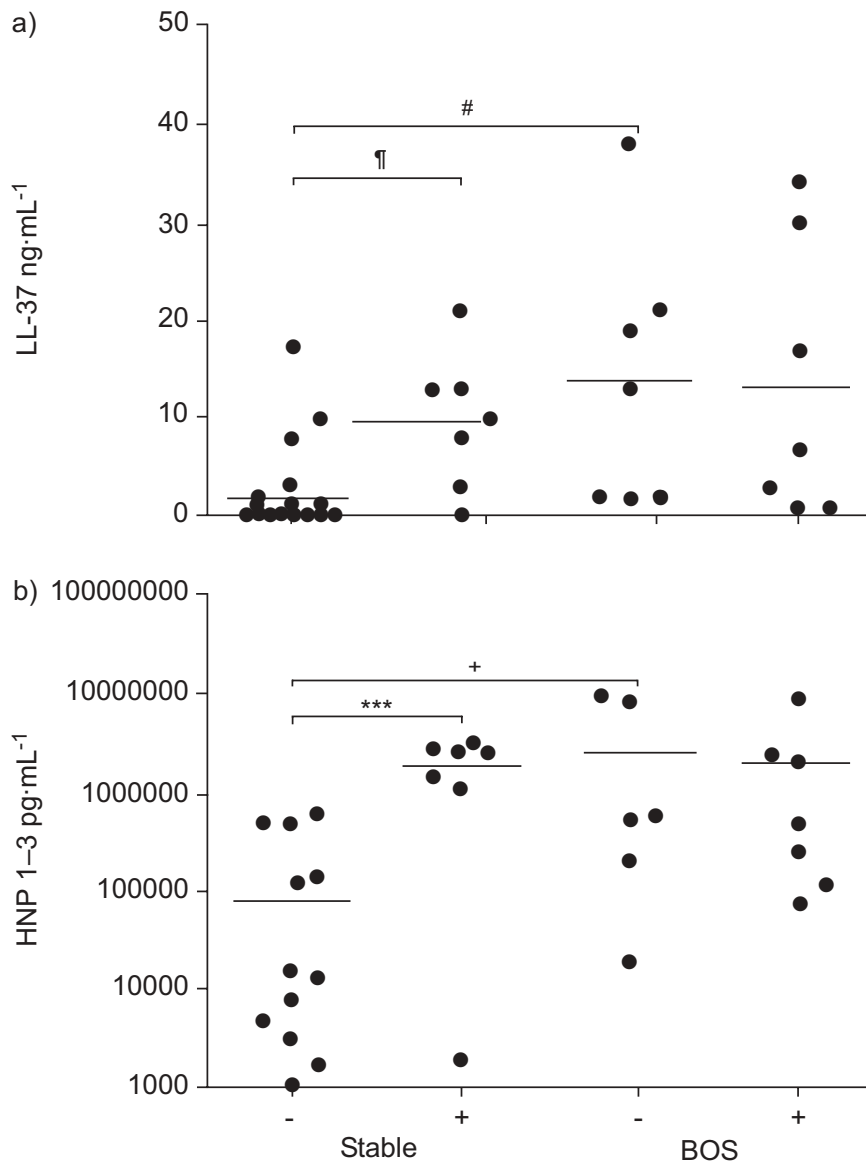

FIGURE 1. Levels of the neutrophil-derived antimicrobial peptides LL-37 and human neutrophil peptides (HNP) 1-3 in bronchoalveolar lavage (BAL) fluid. A comparison is made between four separate groups of transplant recipients, those with stable lung function and no pathogens $(n=23)$, those with stable lung function and pathogens cultured from BAL fluid $(n=7)$, recipients with bronchiolitis obliterans syndrome (BOS) and no pathogens cultured from BAL $(n=8)$ and recipients with BOS and pathogens present on culture of BAL fluid $(n=6)$. -: no pathogen; +: with pathogens. ${ }^{*}: p=0.001 ;{ }^{\bullet}: p=0.002 ;{ }^{+}: p=0.007$. ${ }^{* * *}: p<0.001$. 


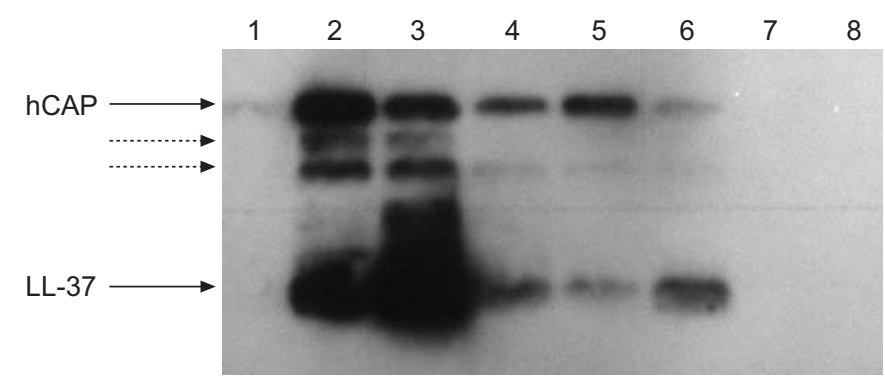

FIGURE 2. Western blot analysis of bronchoalveolar lavage (BAL) samples using monoclonal anti-LL-37 antibody. BAL samples were separated by SDS-PAGE and analysed by Western blot using monoclonal anti-LL-37. Immunoreactive bands were then visualised using enhanced chemiluminesence. Lanes 1-4: recipients with bronchiolitis obliterans syndrome; lanes 5-8: stable recipients. The dotted arrows indicate intermediate processing products. hCAP: human cathelicidin.

of the groups in the present study. In contrast, there were markedly different responses in SLPI expression in stable and BOS recipients. Stable recipients had elevated SLPI in the presence of pathogens, which was not observed in recipients with BOS. In recipients without detectable pathogens, SLPI levels were significantly lower in recipients with BOS compared with those with stable lung function (fig. 4).

\section{DISCUSSION}

The present authors have demonstrated that lung transplant recipients with BOS show a different pattern of antimicrobial peptide expression than stable recipients. BOS is characterised by significantly elevated levels of LL-37 and $\alpha$-defensins HNP $1-3$, and significantly reduced levels of SLPI (fig. 5).

These results correspond with the previous findings by Nelsestuen et al. [29] that, in a proteomic survey of BAL protein content, elevated levels of the $\alpha$-defensins are associated with subsequent development of BOS. Both LL-37 and HNP 1-3 are derived predominantly from neutrophils, although epithelial cells may also contribute to LL-37 levels in airways [15]. hCAP18/LL-37 is stored in the specific granules of neutrophils [28] and is processed to active LL-37 by proteinase-3, although other proteinases may also contribute to processing $[27,30]$. Western blot analysis showed that the ratio between the precursor hCAP-18 and LL-37 differs among transplant recipients irrespective of the presence of BOS and, therefore, provides additional information to that obtained by ELISA. However, because BAL was not collected in a mixture of proteinase inhibitors, the possibility that post-collection processing affected the results can not be excluded. Both HNP1-3 and hCAP-18/LL-37 are released from neutrophils during degranulation. The current results suggest that degranulation of the neutrophils present in the airways of transplant recipients with BOS contributes to ongoing airway injury.

This leads to speculation that elements of the pulmonary innate response play an aetiological role in BOS development. Indeed, Ross et al. [31] showed elevation of hBD-2 in transplant recipients with BOS compared with recipients with stable lung function. However, no elevation of hBD-2 levels was found in patients with BOS. In the study by Ross et al. [31], six out of the eight samples from BOS recipients were culture positive for pathogens. This may account for differences between the

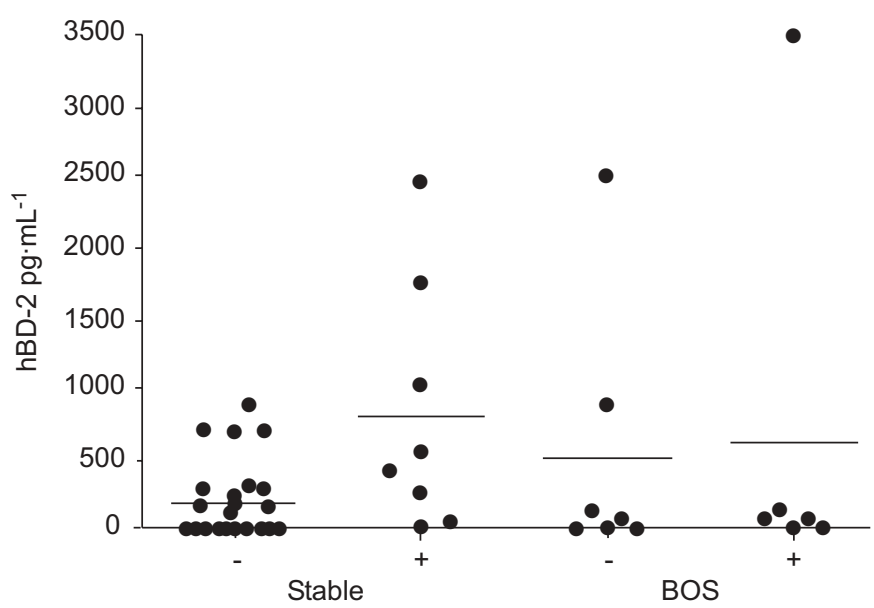

FIGURE 3. Levels of human $\beta$-defensin (hBD)-2 in the four recipient groups. BOS: bronchiolitis obliterans syndrome. -: no pathogens; +: with pathogens.

findings, since epithelial expression of hBD-2 is markedly induced by exposure to microbial products [32, 33]. Indeed, a biologically plausible elevation was observed in the hBD-2 level in stable recipients with infection in comparison to stable recipients without infection; however, this did not reach statistical significance. In contrast, no increase in hBD-2 levels was found in recipients with BOS who had pathogens present. In fact, the current results demonstrated that the presence of pathogens in recipients with BOS was not associated with a significant increase in the level of any of the AMPs measured. This is in marked contrast to the response to pathogens seen in stable recipients. The present authors speculate that in BOS, neutrophil derived AMPs are already abundantly present due to neutrophil degranulation and that no additional response is possible in the presence of pathogens. The lack of response from the epithelial-derived AMPs SLPI, elafin and hBD-2 suggests a blunted epithelial antimicrobial response to pathogens in recipients with BOS.

The significant reduction in SLPI seen in BOS patients is interesting; particularly in the absence of a similar reduction in the other epithelial cell-derived mediators, the related proteinase inhibitor elafin and hBD-2. There are several possible explanations for this finding as the results may reflect reduced production, an increase in cell association or retention of SLPI leading to reduced recovery in BAL, or increased degradation. Nonspecific charge-related retention of AMPs by the inflamed and remodelled airway in BOS cannot explain the current findings since all the AMPs studied were cationic and only SLPI was reduced, whereas other (sometimes more cationic) proteins were stable or even increased.

JAUMANN et al. [34] have previously shown in vitro that transforming growth factor (TGF)- $\beta_{1}$ is a potent inhibitor of SLPI production. There is evidence that the airway environment of transplant recipients is rich in TGF- $\beta_{1}$ [35], suggesting that increased TGF- $\beta_{1}$ levels in BOS may reduce local SLPI production. Increased levels of neutrophil elastase may also explain decreased SLPI levels in BOS, as in cell culture studies neutrophil elastase blocks the release of SLPI from epithelial cells by increasing the amount of cell-associated SLPI [36]. 

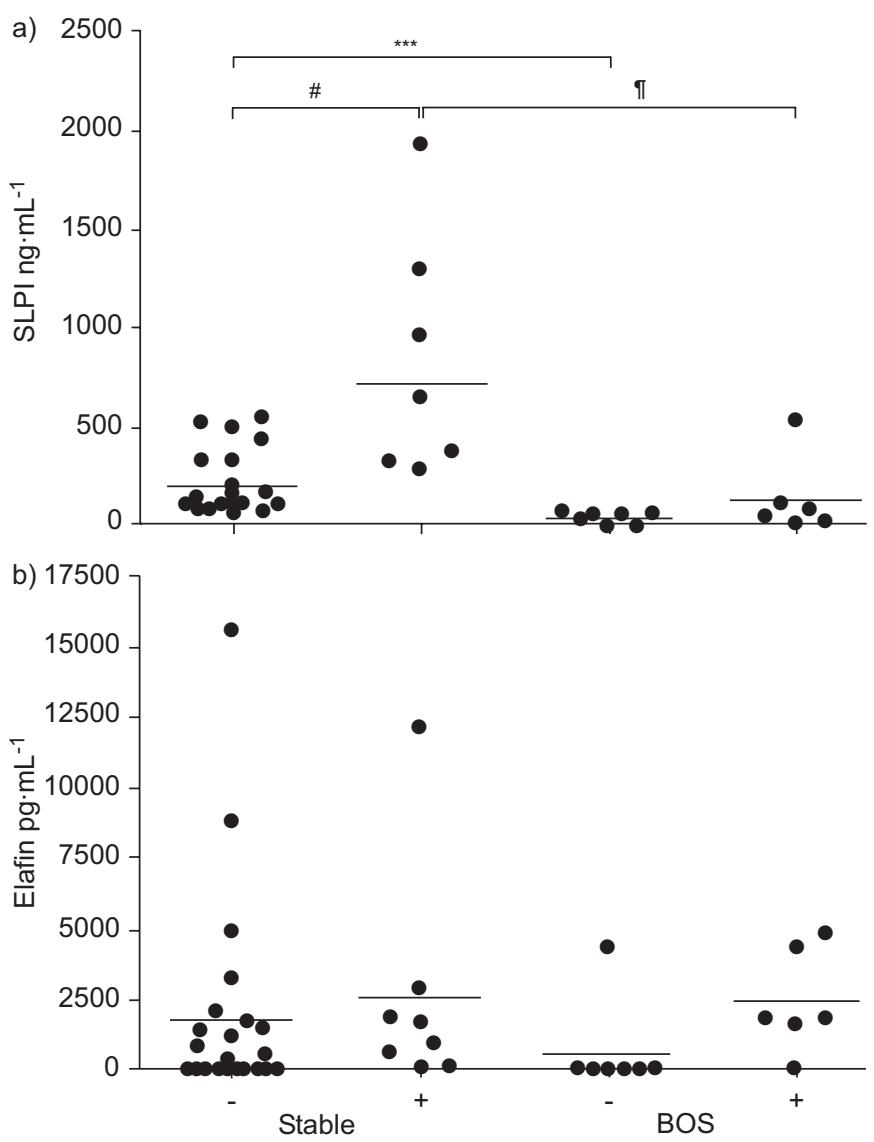

FIGURE 4. Levels of the proteinase inhibitors secretory leukoprotease inhibitor (SLPI) and elafin in each of the four recipient groups. BOS: bronchiolitis obliterans syndrome. -: no pathogens; +: with pathogens. ${ }^{\#}: p=0.001 ; "$ : $p=0.006$ $* * *: p<0.001$

HIRSCH et al. [37] have demonstrated reduced levels of SLPI in lung transplant recipients with BOS that were inversely correlated with the presence of oxidised methionine in BAL fluid. They speculated that oxidative stress in BOS leads to increased consumption of SLPI by proteolytic and oxidative inactivation. The possibility that the lower SLPI levels in BOS patients are explained by degradation of SLPI, as previously shown in cystic fibrosis, was examined in the present study [38]. Therefore, SLPI degradation of products by Western blot analysis of the samples was investigated. Despite the fact that a polyclonal antibody that detects multiple epitopes on SLPI was used, no evidence of SLPI degradation was found in any of the samples assayed. Therefore, the lower SLPI levels in BOS patients are not explained by increased SLPI degradation.

The present authors considered the possibility that the observed differences in AMP levels reflected differing immunosuppressive regimes of stable patients and those with BOS. The overwhelming majority of recipients commenced cyclosporine, azathioprine and prednisolone at the time of transplantation. The most common alterations over time were the removal of azathioprine due to neutropenia, and a switch from cyclosporine to tacrolimus due to side-effects or recurrent acute-rejection episodes. When BAL fluid was obtained most recipients with BOS were on a regime containing a calcineurin
Pro-inflammatory Anti-inflammatory

\begin{tabular}{|c|c|c|c|c|}
\hline Stable & $\begin{array}{l}\alpha \text {-defensins } \\
\text { LL-37 } \\
\text { HNE }\end{array}$ & $=$ & $\begin{array}{l}\text { SLPI } \\
\text { Elafin }\end{array}$ & $\begin{array}{l}\text { Equilibrium between } \\
\text { damage and repair }\end{array}$ \\
\hline $\begin{array}{l}\text { Stable } \\
\text { with } \\
\text { pathogens }\end{array}$ & $\begin{array}{l}\alpha \text {-defensins } \\
\text { ALL-37 } \\
\text { AHNE } \\
\text { AhBD-2 }\end{array}$ & $>$ & $\begin{array}{l}\text { 4SLPI } \\
\text { Elafin }\end{array}$ & $\begin{array}{l}\text { Transient increase } \\
\text { in innate immune } \\
\text { response to deal } \\
\text { with pathogens }\end{array}$ \\
\hline BOS & $\begin{array}{l}\text { 4 } \alpha \text {-defensins } \\
\text { ALL-37 } \\
\text { AHNE }\end{array}$ & $<$ & $\begin{array}{l}\downarrow \text { SLPI } \\
\text { Elafin }\end{array}$ & $\begin{array}{l}\text { Chronic } \\
\text { pro-inflammatory } \\
\text { state promoting } \\
\text { airway damage }\end{array}$ \\
\hline
\end{tabular}

FIGURE 5. Summary of the antimicrobial peptide levels in the different study groups. HNE: human neutrophil elastase; hBD-2: human $\beta$-defensin-2 SLPI: secretory leukoprotease inhibitor.

inhibitor and prednisolone, and most stable recipients were on a regime containing a calcineurin inhibitor, azathioprine and prednisolone. Little is known about the effects of immunosuppressant drugs on AMP levels, but it is unlikely that the higher incidence of azathioprine treatment in the stable group explains the differential pattern of AMP expression found between stable and BOS groups. A limitation of the present study is that it was cross-sectional and so does not examine the changes in AMP levels over time. There was a statistically significant difference between the two study groups in the length of time after transplantation before BAL was collected. Data from a subsequent longitudinal study would further clarify this issue.

The current findings support the hypothesis that, with or without pathogens, in BOS there are elevated levels of the neutrophil-derived AMPs. The presence of high levels of LL-37 and the $\alpha$-defensins would be expected to lead to release of potent chemokines and changes in the maturation and function of dendritic cells $[17,21]$. In addition, these antimicrobial peptides exert chemotactic activity for both dendritic cells and T-cells. Therefore, increased local levels of LL-37 and neutrophil $\alpha$-defensins could increase the initiation and propagation of an adaptive immune response, which may contribute to alloimmune-mediated injury. Both neutrophil $\alpha$-defensins and LL-37 have been shown to affect epithelial wound repair. Specifically, neutrophil defensins are mitogenic for fibroblasts [39] and increase collagen type I and III expression in both dermal and corneal fibroblasts [40, 41], suggesting that increased levels of $\alpha$-defensins may contribute to tissue fibrosis. Therefore, the higher levels of $\alpha$-defensins in transplant recipients with BOS may be associated with an exaggerated repair response to airway damage. The current results also imply that there is a protease/antiprotease imbalance in the airway in BOS with excess free neutrophil elastase present which is not counteracted by SLPI. This situation would be expected to contribute to further airway damage and inflammation. If the level of SLPI in the airway is truly reduced then the consequences of this would be reduced antimicrobial defence with risk of further infections perpetuating airway inflammation, and decreased protection against neutrophil-derived proteinase inhibitors with decreased epithelial repair. 
In summary, the antimicrobial peptide responses demonstrated in bronchiolitis obliterans syndrome will contribute to a pro-inflammatory microenvironment and may promote alloimmune injury and an exaggerated repair response, which could drive the airway remodelling characteristic of bronchiolitis obliterans syndrome. Treatment approaches which address abnormalities in innate immune responses in lung transplant recipients may be important in protecting the graft and require more evaluation.

\section{ACKNOWLEDGEMENTS}

The present authors would like to thank G. Johnson, L. Archer, K. Gould (all Cardiopulmonary Transplant Unit, Freeman Hospital, Newcastle upon Tyne, UK), D. Ninaber, B. van der Linden and R. Verhoosel (Dept of Pulmonology, Leiden University Meical Centre, Leiden, The Netherlands) for valuable technical assistance.

\section{REFERENCES}

1 Estenne M, Hertz MI. Bronchiolitis obliterans after human lung transplantation. Am J Respir Crit Care Med 2002; 166: 440-444.

2 Trulock EP, Edwards LB, Taylor DO, Boucek MM, Keck BM, Hertz MI. Registry of the international society for heart and lung transplantation: twenty-second official adult lung and heart-lung transplant report - 2005. J Heart Lung Transplant 2005; 24: 956-967.

3 Husain AN, Siddiqui MT, Holmes EW, et al. Analysis of risk factors for the development of bronchiolitis obliterans syndrome. Am J Respir Crit Care Med 1999; 159: 829-833.

4 Khalifah AP, Hachem RR, Chakinala MM, et al. Minimal acute rejection after lung transplantation: a risk for bronchiolitis obliterans syndrome. Am J Transplant 2005; 5: 2022-2030.

5 Boehler A, Estenne M. Obliterative bronchiolitis after lung transplantation. Curr Opin Pulm Med 2000; 6: 133-139.

6 DiGiovine B, Lynch JP 3rd, Martinez FJ, et al. Bronchoalveolar lavage neutrophilia is associated with obliterative bronchiolitis after lung transplantation: role of IL-8. J Immunol 1996; 157: 4194-4202.

7 Ward C, Snell GI, Zheng L, et al. Endobronchial biopsy and bronchoalveolar lavage in stable lung transplant recipients and chronic rejection. Am J Respir Crit Care Med 1998; 158: 84-91.

8 Riise GC, Williams A, Kjellstrom C, Schersten H, Andersson BA, Kelly FJ. Bronchiolitis obliterans syndrome in lung transplant recipients is associated with increased neutrophil activity and decreased antioxidant status in the lung. Eur Respir J 1998; 12: 82-88.

9 Zheng L, Whitford HM, Orsida B, et al. The dynamics and associations of airway neutrophilia post lung transplantation. Am J Transplant 2006; 6: 599-608.

10 McNeil K, Glanville AR, Wahlers T, et al. Comparison of mycophenolate mofetil and azathioprine for prevention of bronchiolitis obliterans syndrome in de novo lung transplant recipients. Transplantation 2006; 81: 998-1003.

11 Matzinger P. The danger model: a renewed sense of self. Science 2002; 296: 301-305.
12 Bals R, Hiemstra PS. Innate immunity in the lung: how epithelial cells fight against respiratory pathogens. Eur Respir J 2004; 23: 327-333.

13 Yang D, Biragyn A, Hoover DM, Lubkowski J, Oppenheim JJ. Multiple roles of antimicrobial defensins, cathelicidins, and eosinophil-derived neurotoxin in host defense. Annu Rev Immunol 2004; 22: 181-215.

14 Ganz T, Selsted ME, Szklarek D, et al. Defensins. Natural peptide antibiotics of human neutrophils. J Clin Invest 1985; 76: 1427-1435.

15 Bals R, Wang X, Zasloff M, Wilson JM. The peptide antibiotic LL-37/hCAP-18 is expressed in epithelia of the human lung where it has broad antimicrobial activity at the airway surface. Proc Natl Acad Sci USA 1998; 95: 9541-9546.

16 Ganz T. Defensins: antimicrobial peptides of innate immunity. Nat Rev Immunol 2003; 3: 710-720.

17 Davidson DJ, Currie AJ, Reid GS, et al. The cationic antimicrobial peptide LL-37 modulates dendritic cell differentiation and dendritic cell-induced T-cell polarization. J Immunol 2004; 172: 1146-1156.

18 van Wetering S, Tjabringa GS, Hiemstra PS. Interactions between neutrophil-derived antimicrobial peptides and airway epithelial cells. J Leukoc Biol 2005; 77: 444-450.

19 Bowdish DM, Davidson DJ, Lau YE, Lee K, Scott MG, Hancock RE. Impact of LL-37 on anti-infective immunity. J Leukoc Biol 2005; 77: 451-459.

20 Selsted ME, Ouellette AJ. Mammalian defensins in the antimicrobial immune response. Nat Immunol 2005; 6: 551-557.

21 Oppenheim JJ, Yang D. Alarmins: chemotactic activators of immune responses. Curr Opin Immunol 2005; 17: 359-365.

22 Estenne M, Maurer JR, Boehler A, et al. Bronchiolitis obliterans syndrome 2001: an update of the diagnostic criteria. J Heart Lung Transplant 2002; 21: 297-310.

23 Haslam PL, Baughman RP. Report of ERS Task Force: guidelines for measurement of acellular components and standardization of BAL. Eur Respir J 1999; 14: 245-248.

24 Proud D, Sanders SP, Wiehler S. Human rhinovirus infection induces airway epithelial cell production of human $\beta$-defensin 2 both in vitro and in vivo. J Immunol 2004; 172: 4637-4645.

25 Tjabringa GS, Vos JB, Olthuis D, et al. Host defense effector molecules in mucosal secretions. FEMS Immunol Med Microbiol 2005; 45: 151-158.

26 Kramps JA, Franken C, Dijkman JH. ELISA for quantitative measurement of low-molecular-weight bronchial protease inhibitor in human sputum. Am Rev Respir Dis 1984; 129: 959-963.

27 Sorensen OE, Follin P, Johnsen AH, et al. Human cathelicidin, hCAP-18, is processed to the antimicrobial peptide LL-37 by extracellular cleavage with proteinase 3 . Blood 2001; 97: 3951-3959.

28 Sorensen O, Arnljots K, Cowland JB, Bainton DF, Borregaard N. The human antibacterial cathelicidin, hCAP-18, is synthesized in myelocytes and metamyelocytes and localized to specific granules in neutrophils. Blood 1997; 90: 2796-2803.

29 Nelsestuen GL, Martinez MB, Hertz MI, Savik K, Wendt $\mathrm{CH}$. Proteomic identification of human neutrophil 
$\alpha$-defensins in chronic lung allograft rejection. Proteomics 2005; 5: 1705-1713.

30 de Haar SF, Hiemstra PS, van Steenbergen MT, Everts V, Beertsen W. Role of polymorphonuclear leukocyte-derived serine proteinases in defense against actinobacillus actinomycetemcomitans. Infect Immun 2006; 74: 5284-5291.

31 Ross DJ, Cole AM, Yoshioka D, et al. Increased bronchoalveolar lavage human $\beta$-defensin type 2 in bronchiolitis obliterans syndrome after lung transplantation. Transplantation 2004; 78: 1222-1224.

32 Tsutsumi-Ishii Y, Nagaoka I. NF-кB-mediated transcriptional regulation of human $\beta$-defensin-2 gene following lipopolysaccharide stimulation. J Leukoc Biol 2002; 71: 154-162.

33 Harder J, Meyer-Hoffert U, Teran LM, et al. Mucoid Pseudomonas aeruginosa, TNF- $\alpha$, and IL-1 $\beta$, but not IL-6, induce human $\beta$-defensin-2 in respiratory epithelia. Am J Respir Cell Mol Biol 2000; 22: 714-721.

34 Jaumann F, Elssner A, Mazur G, Dobmann S, Vogelmeier C. Transforming growth factor- $\beta 1$ is a potent inhibitor of secretory leukoprotease inhibitor expression in a bronchial epithelial cell line. Munich lung transplant group. Eur Respir J 2000; 15: 1052-1057.

35 Elssner A, Jaumann F, Dobmann S, et al. Elevated levels of interleukin- 8 and transforming growth factor- $\beta$ in bronchoalveolar lavage fluid from patients with bronchiolitis obliterans syndrome: proinflammatory role of bronchial epithelial cells. Munich lung transplant group. Transplantation 2000; 70: 362-367.

36 van Wetering S, van der Linden AC, van Sterkenburg MA, Rabe KF, Schalkwijk J, Hiemstra PS. Regulation of secretory leukocyte proteinase inhibitor (SLPI) production by human bronchial epithelial cells: increase of cellassociated SLPI by neutrophil elastase. I Investig Med 2000; 48: 359-366.

37 Hirsch J, Elssner A, Mazur G, et al. Bronchiolitis obliterans syndrome after (heart-)lung transplantation. Impaired antiprotease defense and increased oxidant activity. Am J Respir Crit Care Med 1999; 160: 1640-1646.

38 Birrer P, McElvaney NG, Rudeberg A, et al. Proteaseantiprotease imbalance in the lungs of children with cystic fibrosis. Am J Respir Crit Care Med 1994; 150: 207-213.

39 Murphy CJ, Foster BA, Mannis MJ, Selsted ME, Reid TW. Defensins are mitogenic for epithelial cells and fibroblasts. J Cell Physiol 1993; 155: 408-413.

$40 \mathrm{Li} \mathrm{J}$, Raghunath M, Tan D, Lareu RR, Chen Z, Beuerman RW. Defensins HNP1 and hBD2 stimulation of wound-associated responses in human conjunctival fibroblasts. Invest Ophthalmol Vis Sci 2006; 47: 3811-3819.

41 Oono T, Shirafuji Y, Huh WK, Akiyama H, Iwatsuki K. Effects of human neutrophil peptide-1 on the expression of interstitial collagenase and type I collagen in human dermal fibroblasts. Arch Dermatol Res 2002; 294: 185-189. 